\title{
The Linguistic Friction in Algeria
}

\begin{abstract}
The purpose of the current study is to compare Modern Standard Arabic and Algerian Arabic with Educated Spoken Arabic at the phonological level and check if there are differences between the three varieties of Arabic at the above level. It aims to describe some aspects of the sociolinguistic situation in Algeria, and to give an overall idea about the linguistic complexity from which Educated Spoken Arabic emerges. Today's educated generation manifests an overt tendency towards the use of a third and intermediate level of Arabic in their daily speeches. This verbal behaviour is a clear evidence of the linguistic change undergone by my informants in the realm of phonology and lexis. The linguistic usage of one level of Arabic at the expense of other levels can be accounted for by socio-cultural phenomena such as Arabization, i.e. act of identity. The friction between Classic/Modern Standard Arabic and dialectal Arabic is supposed to be lessened by a third level of Arabic, commonly known as Educated Spoken Arabic. This study mainly focus on the defining characteristics of Classical Arabic, Modern Standard Arabic, Algerian Arabic and the impact of the Arabization policy on the Algerian social strata. This research also attempts to demonstrate the heterogeneity of Educated Spoken Arabic particularly at the phonological and lexical levels. Some morphological features will also be discussed in order to show its appropriateness and intelligibility to a large segment of the Algerian society.
\end{abstract}

Keywords: code switching, levels of arabic, bilingualism, diglossia, educated spoken arabic, language policy, arabization, language management, dialect, phonology
Volume 2 Issue 2 - 2018

\section{Kerma Mokhtar}

Department of Sociology, University of Oran 2, Algeria

Correspondence: Kerma Mokhtar, Department of Sociology, University of Oran 2, Algeria, Tel +213 669023530,

Email kerma.mokhtar@gmail.com

Received: December 30, 2017 | Published: April 25, 2018

\section{Introduction}

The linguistic situation in Algeria is varied and complex in the sense that several varieties are used today namely Classical Arabic, Modern Standard Arabic, Colloquial Arabic, Educated Spoken Arabic, Berder and its varieties, i.e. Chawi, Mzabi and Tergui, French, some Spanish, and lately English, particularly in the field of commerce, science and technology. Accordingly, Algeria is characterised by the phenomenon of multilingualism which affects the socio- cultural life of the Algerianpeople, and gives rise to sociolinguistic needs that must be taken into account in education and language planning. This paper addresses the issue of conflict and rivalry concerning the functions and statuses of the languages used in Algeria, namely Classical/ Modern Standard Arabic, Algerian Arabic, Berber, and French. Such friction might have negative consequences on the fabric of the Algerian society in the future. This article deals with the historical and sociocultural background. It will shed light on the sociolinguistic context in which Arabization has been implemented, as well as on the educational system in Algeria, and the attempts made to revitalize Modern Standard Arabic as a means of instruction. Focus will be on some obstacles which hamper a successful Arabization, chiefly the language contact and the language conflict in a sociolinguistic context where languages (and dialects) compete to attain higher status. The data is drawn from a wide variety of sources, including field work, interviews and related research literature. In spite of the linguistic diversity, the Algerian decision- makers adopted in 1963 Classical / Modern Standard Arabic as the National and official language of Algeria (Art.3, constitution), and avoidedthe whole question of the social valuation of such a choice which, as we shall see later, has sociolinguistic implications on the different strata of the Algerian people. In fact, this choice is subjective rather than linguistic. The Algerian society is homogenised around one language "Arabic". The latter became the ralling point of all the forces of the nation, but of which "Arabic" are we speaking? Is it the " super- imposed" variety which we referred to earlier as Classical/Modern Standard Arabic? (hereafter CA/MSA) Or is it the native variety of Arabic spoken by the majority of the Algerian people, commonly known as Algerian Arabic? (hereafter AA). It is interesting to notice that because of the excessive purism that prevailed at that time, there is no doubt about the fact that the only variety of Arabic that could unite the nation's efforts in its fight for sweeping the vestiges of colonialism was CA/ MSA, the language of "Arab-patriotism" and "Pan- Arab Unity". Political circles labelled CA/MSA the standard language and labelled AA a dialect, but socio-political imperatives and social needs do not always merge. A new form of Arabic is emerging in Algeria, and the Arab world in general as a suitable means of communication. This medium is labelled differently as "Middle Arabic",/allugha al wuTa / or ESA. Before considering whether or not CA has undergone a partial shift from classicism to Eduated Spoken Arabic( hereafter ESA).Let us first define CA, MSA, and AA.

\section{Classical arabic}

The term "Arabic" refers to the classical or archaic forms used in the Mosque for relegious ceremonies, and at home for worship. CA is used for prayers by Moslems all over the world whatever their mother tongue may be: "Classical Arabic is used by approximately one billion Muslims for prayer and scholarly religious discourse."Houghton and Miflin ( 1994:412). Classical Arabic is codified and is the vehicule of a huge body of classical literature. It has a great literary tradition encompassed in ancient poetry, religious and grammar books. CA enjoys the prestige of a written language , but is no one's mother tongue. It is used by a group of scholars who have always taken great pride in their ability to speak flawless Arabic, and therefore always looked down upon any colloquial interference whith the classical forms. In addition, CA is said to be the language 
of formal discourse, lectures, news broadcasts, speeches and the like. However, under the new regime which has emerged during and after the Algerian revolution (1954-1962) there has been a clash between revolutionary leaders and the traditional classicists to meet the new social requirement namely illeteracy and unemployment.

For instance, a shift from the use of the case-endings is a striking example (Table1).

Table I Case-ending inflection

\begin{tabular}{|c|c|c|}
\hline CA & MSA & Gloss \\
\hline [Өu: mun] & {$[\theta u: m]$} & garlil \\
\hline [૪ i ðæ :? un] & [૪ і ðæ :?] & food \\
\hline [3amalun] & [ zamal] & a camel \\
\hline
\end{tabular}

From the above examples CA has undergone a partial shift from classicism to MSA, but the classicists continued to frown upon what they considered a gross violation of the classical style. As a result of this clash, a linguistic revolution began to take shape. As time went on the traditional Arab classicists were gradually displaced and the "neo-classicists" took over to adapt Arabic vocabulary to the pressing demands of modern scientific technology. In fact, there is some gradual loss of the most archaic vocabulary and phonetic and morphological structures of CA, because these are too far from today's reality.

\section{Modern standard arabic}

Arabic advocated by the Algerian rulers is not CA as it may be seen, but it is a modern literary form derived from it to meet social and linguistic needs. This contemporary variety of Arabic, which is definitely less formal than $\mathrm{CA}$, has a higher rate of frequency. ${ }^{1} \mathrm{~A}$ huge number of foreign words and expressions was introduced into Arabic during the $19^{\text {th }}$ century. Hence,they gave birth to MSA.The label Modern Standard Arabic has been applied to the written language of contemporary literature, journalism, some political speeches, television and radio newscast, administration and diplomacy. It serves as the vehicle for current forms of literature, and seen as a resource language for communication between literate Algerians. Saïd ${ }^{2}$ states that MSA is: "that variety of Arabic that is found in contemporary books, newspapers, and magazines, and that is used orally in formal speeches, public lectures, and television."MSA is a streamlined, modernised form of CA. It is the official language of all Arab countries, and the understandable means of communication within the Arab world. MSA is standardised and codified to the extent that it can be understood by different Arabic speakers in the Arab World at large.It has the defining characteristic of a modern language serving as the vehicle of a universal literature. A great deal of scholarly attention has been paid in Western countries to the study of Arabic in its many forms from a linguistic point of view. Linguists attempted to describe the results of the operation of some of the factors; lexical and syntactical, native and foreign which influence MSA and attempted to specify some of the features which distinguish it from CA.

\section{MSA vs CA}

Modern Standard Arabic and Classical Arabic are usually perceived as one. ${ }^{3}$ states that "Ordinary Arabs themselves do not make a systematic terminological differentiation between CLA and MSA. Both are termed Pal'arabi:yatuIfuşha: "pureleloquent
Arabic" or simply Pl'arabi:yaor Pal fuşha: for short, in Opposition to Pl'a:mmi:ya 'the vernacular', which exists in innumerable varieties and is popularly thought to be a grammarless corruption of "real "Arabic(Palfuşha:)." MSA is formally similar, but not identical to CA. The main difference between MSA and CA lies in the vocabulary since they represent the written traditions of very different historical and cultural eras, from the early medieval period to the modern. MSA reflects the need of contemparary expressions, whereas CA reflects the need of older styles. MSA relies heavily on translation from French and English. A wide range of new lexical items is adopted by MSA. Mary Catherine Bateson ${ }^{4}$ identified three kinds of change that differentiate MSA from CA:

a. A "series of 'acceptable' simplifications" in syntactic structures.

b. A "vast shift in the lexicon due to the need for technical terminology

c. A "number of stylistic changes due to translations from European languages

d. Extensive bilingualism.

The major differences are stylistic and lexical rather than grammatical. Particular features of MSA journalistic style include more flexible word order, coinage of neologisms, and loan translations from western languages. For instance, we frequently hear on the Algerian radio and television (Table 2)(Table 3).

Table 2 Features of MSA

\begin{tabular}{lll}
\hline MSA & French & Origin gloss \\
\hline [sikriti:r] & Secrètaire & secretary \\
[Libera:li] & libèral & liberal \\
[mikænizm] & Mècanisme & mechanism \\
\hline
\end{tabular}

Table 3 Loan translations from western languages

\begin{tabular}{ll}
\hline MSA & English origin \\
\hline [kæmpju:tar] & Computer \\
[manæ 3 ment] & management \\
?æfla:m [lwæstæ:rn] & western films \\
\hline
\end{tabular}

Morphologically, MSA does not make extensive use of the case endings that are prevalent in CA (Table 4).

Table 4 Comparing CA and MSA morphologically

\begin{tabular}{|c|c|c|}
\hline CA & MSA & Gloss \\
\hline [mæktæbun] & [mæktๆb] & a desk \\
\hline [qalæmun ] & [qæl Пm] & a pen \\
\hline [wælædun] & [wæl Ød] & a boy \\
\hline
\end{tabular}

\section{The salient characteristics of MSA}

MSA is standardised and codified. It has its own grammar and lexicon. It possesses: standardisation, historicity and autonomy, but it lacks vitality now. MSA is an idealised language. It has no native speakers. Mitchell(1974:124) states that: "Modern Standard Arabic is not a spoken language, it is nobody's mother tongue, and the man who wants to talk at all times like abook or a newspaper is a decided oddity." It is not secret that, relatively speaking, very few 
Algerians can really master MSA in such a way as to be able to engage extemporaneously in literary activities, or participate in public formal discourses. Most Algerian people seem to have a passive knowledge of MSA in the sense that they can neither speak, nor write it properly. Achouche ${ }^{5}$ states that: "An Algerian reader whose level of education equivalen to the Baccalauriate can not read a page of an Arabic newspaper without making mistakes of interpretation. "Quoated in Ennaji ${ }^{6}$ This is due to the rigid morphology of MSA. Even lawyers and civil servants can not read it properly without making serious pronunciation or grammatical mistakes. This may be caused partly by the lack of vowel indication (Tashkeel) (Table 5).

Table 5 Comparing ESA and MSA morphologically

\begin{tabular}{lll}
\hline ESA & MSA & Gloss \\
\hline [3 æ:na & {$[3$ æ:?æna] } & we received \\
[nætia mæl] & {$[$ nætæ[a:mæl] } & we deal with \\
[3 di:d] & [3ædi:d] & new \\
\hline
\end{tabular}

\section{Language use}

Since the end of colonialism, the Algerian governements have initiated mass-education campaigns. This is clearly obvious in the educational system of the country. MSA is introduced at school as a unifying language. All Algerians from six years on are required by law to acquire basic knowledge through the medium of MSA. Such a policy is assumed to overcome the linguistic regionalism, and to open doors to a new era of linguistic stability, covering the different parts of Algeria. But MSA is never used outside the school for any purpose. Pupils are torn between the diglossic reality whereby they "must" use MSA to write and communicate in formal situations, and use the vernacular to communicate in informal situations. Six years old children are confronted with new vocabulary which is hardly related to their mother tongue. Consider the following examples (Table 6). MSA failed to come to terms with the linguistic diversity in Algeria, particularly Berber which is flourishing in the present linguistic climate. It therefore seems to move from what is supposed to be a constant language to subordinate one. Table 1.1 is based on responses to a questionnaire administrated to a sample of 40 informants from different parts of Algeria. It shows a decreasing percentage of MSA users.

Table 6 Comparing MSA and AA

\begin{tabular}{lll}
\hline MSA & AA & Gloss \\
\hline$[$ [i 3 lis $]$ & [ gfud] & sit dow \\
[yira: ?] & [lsæ:q] [ kola] & Glue \\
[miizar] & [tablija] & a pinafore \\
\hline
\end{tabular}

Table 7 Do you like communicating in MSA?

\begin{tabular}{|c|c|c|c|}
\hline & Age-group & \multirow{2}{*}{ Total } & \multirow{2}{*}{$\%$} \\
\hline & $17 / 25$ 26/35 36/50 50+ & & \\
\hline Yes & 1332 & 9 & 22,5 \\
\hline Blanks & 3021 & 6 & 15 \\
\hline No & 6757 & 25 & 62,5 \\
\hline
\end{tabular}

Total number of informants: 40
$62,5 \%$ of may informants dislike communicating in MSA on the basis that it is a boring language far from their mother tongue namely dialectal Arabic and Berber. MSA's influence is manifested in 22,5 percent of my total informants. They are eager to activate the role of MSA whithin the Algerian society. But are Algerian people ready to reject their mother tongue and embrace MSA as the sole medium of communication in Algeria? Besides, the establishment of MSA as the official and national language of Algeria would block social mobility of AA and Berber.

\section{Algerian arabic}

Algerian Arabic is the mother tongue of the vast majority of the Algerian people. It refers to the variety that Algerians use in oral communication. It is a Colloquial Arabic used for everyday-life situations and all interpersonal interactions. It is unwritten although one might encounter an informal written text in the Arabic script The few cases when Algerian Arabic was written down can be traced back to the 80's and 90's now extenct, satirical newspapers such as: EL Munshar, EL Quardash and Sah Afa. To those, one might add the radio plays in AA, which must have been written down (even though never published) at least for the benefit of the cast. Bedouin poetry and soap operas are striking examples. Bishai ${ }^{7}$ states that: "Desirous of reaching the general public and perhaps also because they hadnot fully mastered $C A$ the speakers of the revolutions have often usedcolloquial expression in theirformal speech. "Algerian Arabic is still written in many newspapers today El-haddaf and Ech-chabka are sriking examples.

\section{The salient characteristic of AA}

Algerian Arabic is different from CA/MSA on the phonological, morphological,syntactical and lexical levels. Phonologically, most MSA vowels are deleted or reduced to schwa in AA.The following are representative examples (Table 8).

Table 8 Comparing MSA and AA

\begin{tabular}{lll}
\hline MSA & AA & Gloss \\
\hline [rasama $]$ & {$[$ rsam $]$} & he draw \\
[fæhima $]$ & {$[$ fhæm $]$} & he understood \\
[rabiha $]$ & {$[$ rbæh $]$} & he won \\
\hline
\end{tabular}

Morphologically, AA is much simpler than MSA because of the absence of case-marking inflections and the dual and feminine plural inflections (Table 9).

Table 9 Comparing MSA and AA morphologically

\begin{tabular}{lll}
\hline MSA & AA & Gloss \\
\hline [wælæd] & [wæld] & a boy \\
[bintæ:n] & [zu:3 bnæ:t] & two girls \\
[mæktæbætæ:n] & [zu:3 mæktæbæ:t] & two libraries \\
\hline
\end{tabular}

Syntactical,although both MSA and AA have VSO and SVO word order, the latter is more dominant in AA as in (Table 10):

Table 10 Comparing MSA and AA syntactically

\begin{tabular}{lll}
\hline MSA & AA & Gloss \\
\hline [iftrara Pæbi saja:ra] & [bba Jra loto] & my father bought a car \\
\hline
\end{tabular}


Lexically, AA is characterised by borrowing, particularly from French . The following are representative examples (Table 11).

Table I I Comparing MSA and AA lexically

\begin{tabular}{lll}
\hline AA & French origin & Gloss \\
\hline [vista] & veste & a jacket \\
[livri] & livre & a book \\
[loto] & auto & a car \\
\hline
\end{tabular}

AA and MSA remain two distinct varieties because:

a. The first is the native language of most Algerians while the second is a super-imposed variety learned at school, and used only for specific purposes

b. The two varieties assume different functions: dialectal Arabic is the language of the home and street, while MSA is the language of Arabization and of modern culture

Dialectal Arabic has recently been appreciated by many scholars. Mazouni ${ }^{8}$ writes that: "Dialectal Arabic in Algeria is one of the defining features of the Algerian people andthe native language of the majority of the population." He suggests that: "Instead of disparaging it, Dialectal Arabic should be studied and used as an aid to develop Modern Standard Arabic."Although it is the actual pillar of communication, AA is considered by my respondents as a distorted dialect of MSA Linguistically speaking, Algerian Arabic has gone through a natural linguistic evolution process that has left it as different from MSA, as modern French, Spanish or Italian are different from Latin (Table 12).

Table 12 Is Algerian Arabic an autonomous language?

\begin{tabular}{|c|c|c|c|}
\hline & Age group & \multirow{2}{*}{ Total } & \multirow{2}{*}{$\%$} \\
\hline & $17 / 25$ 26/35 36/50 50+ & & \\
\hline Yes & 1320 & 6 & 15 \\
\hline Blanks & 1001 & 2 & 5 \\
\hline No & 8789 & 32 & 80 \\
\hline
\end{tabular}

Algerian Arabic is unstable, in that it is in a state of considerable change. According to my informants 80 percent state that $\mathrm{AA}$ is stigmatised essentially because it is not codified. Besides, an individual who knowns only AA is considered as illiterate for the simple reason that AA is not taught at school. Besides, the International Conference on Arabization held in Tripoli in 1975 urged governments to stop the use of dialectal Arabic in arts, novels and plays. But sometimes the speaker is forced to use AA against his wish because the later is the only language which through constant use has kept up to date with the realities of modern life. Practically speaking, despite its belonging to an oral tradition, which relegates it to an inferior position, in the years to come AA will flourish even more, in view of its increasing importance in domains like the family the theatre and the mass-media, namely newspapers such as El haddaf and echabka and many radio and television programmes discussing social political and religious matters.

\section{Arabization}

The Arabization of Algeria started before its independence in 1962, under the leadership of the "Association of Moslem Scholars" in 1931. Arabization sprang from the assumption that any independent sovereign nation needs to have its own language : " Every self respecting nation has to have a language. Not just a medium of communication a 'vernacular' or a'dialect' but a fully developed language" Haugen 9 Quoed in Pride \& Holmes. ${ }^{10}$ The Arabization policy was meant to erase all the coloniser's remnants on the one hand, and to unify Algerians politically and linguistically on the other hand . Hence "The linguistic field" and also " the fieldpower" as put by Andre Miguel. ${ }^{11}$ The former president Ben Bella promised from the eve of independence that (Arabic will regain its rank) (Maarouf) in. ${ }^{12}$ The Algerian Constitutions state in the third article that Arabic is the National and official language of Algeria. In a famous speech, the late President Boumedienne said in 1968:(Without the recovery of this essential and important element which is the national language, our efforts remain in vain, our personality incomplete and our entity a body without soul). From a cultural point of view Algerians define themselves as Arabs and Moslems. The Algerian decisionmakers had a strong will to regain their Arab and Moslem identity. The achievement of such an ideal could not be established without "Arabic". The latter is assumed to be a functional instrument in all spheres of society, particularly in administration, the mass media and shool. Accordingly, Arabization became an urgency. Ibrahimi ${ }^{13}$ said that the necessary policy was "Arabiser progressivement mais résolument." (Arabise progressively but resolutely). Harsh ideological debates were lauched between the ruling elite and the Opposition: "Officials, in independent Algeria, react in ahostile way to French and are very keen onseeing it replaced by the national language, Arabic". ${ }^{14}$ Arabization was super imposed by the Algerian rulers. Such a choice sprung from their socio-political ideologies such Arabo-Islamism and Pan-Arabism. They decided that "Arabic" is a prestigious language which could fulfill all modern, scientific and technological needs, and proposed that French be kept as an "instrument". The priority was to regain the Arabo-Islamic identity which could not be achieved without adequate supports for Arabic.

\section{Steps of arabization}

Under the influence of the late president Boumedienne, 1971 was the year of complete Arabization of the Algerian society. Scientific and literary subject matters were taught in Arabic. Polytechnic education was introduced for the first time in Algeria, and many university departments were gradually Arabised. Besides, manyEgyptian and Iraki teachers of Arabic were brought to Algeria to impliment the Arabization policy. In 1991 the generalisation of Arabic was voted in Parliament (Article ${ }^{\circ}{ }^{29}$ ). Accordingly, any document not written in Arabic was automatically rejected. Besides, a higher Council for Arabicwascreated through a presidential decree to implement the use of Arabicin Algeria. These measures were backed up by a presidential decree, issued in 1998, to generalise Arabic to all spheres of the Algerian society. In spite of the slogan of Arabization and the successive laws to implement it many public offices still use French as a medium in their daily written documents. The post-office and the bank are striking examples. Similarly, private institutions use French in their daily transactions. Arabization was introduced to serve the purpose of administration, schooling, and the mass-media to unite the medium of communication within the Algerian society. But to the best of our knowledge, Arabization is a source of conflict and desagreement among the Algerian people. Therefore, Arabization necessitates a strong will on the part of the civil servants.

The Arabization attempts faced many difficulties and criticisms. Most of my respondents believe that "Arabic" is complex and difficult to learn. This fact is well noticed in their speeches, where a special 
register is used, i.e. a mixture of MSA, AA and some French to meet the communicative needs of modern life. Younger informants (Table 1.3) consider that limitation to one level of Arabic, i.e. MSA is a disadvantage and gave ressons of the type:

a. Arabic is an old fashioned language

b. Making bad impression

c. Problems with the opposite sex (Table 13).

Table 13 It is an advantage or disadvantage to use MSA?

\begin{tabular}{lllll}
\hline & I 7/25 26/35 36/50 50+ & Total & $\%$ \\
\hline Advantage & 1 & 212 & 6 & 15 \\
Neither & 0223 & 7 & 17,5 \\
Disadvantage & 9675 & 27 & 67,5
\end{tabular}

\section{Reaction to Arabization}

Independence was a turning point in the linguistic history of Algeria. By stating that "Arabic" is the National and Official language of Algeria", the legislators of the new Algerian Republic (proclaimed on July 5,1962 ) brought to the surface the strong political and cultural movement towards Arabization that existed with ups-and-downs before independence.

Two kinds of difficulties may be singled out: social and technical. The Algerian rulers imposed MSA in Algeria. Hence, Arabization could not be easily achieved. MSA has no speech conmmunity since it lacks vitality. Besides, large semantic differences between MSA and AA are real obstacle to the spread of MSA into the different levels of the Algerian society. Arabization did not receive the apporoval of the whole educated elited. Grandguillaume ${ }^{11}$ states that student are against it at $80 \%$ in 1967.

The 1996's Arabization Law was, and still is, at the origin of political conflicts. Harsh debates were launched, particularly through newspapers showing strong disapproval of the Arabization policy. In 1997 a journalist said: (Please, when you are addressing people use a simplelanguage, a language that could be understood by everybody, use an Algerian Arabic) Le quotidien d'Oran (1997:4)

One of my respondents said that: "My spoken variety is Algerian Arabic, thelanguage of everyday life, business and socialisation, etc."

Furthermore, a Member of Partiament urged people to go on strike, and show their disapproval through demonstration in the streets. Accordingly, Arabization created a split between advocates of "Arabic" and their antagonists.

Most of my informants showed little or no interest in the Arabization process. Only 8 out of 40 respondents showed their concern about Arabization (Table 14).

Table 14 Are you for or against Arabisation in Algeria?

\begin{tabular}{lll} 
& \multicolumn{1}{c}{ Age group } & Total \\
\cline { 2 - 3 } & $\mathbf{1 7 / 2 5 2 6 / 3 5 3 6 / 5 0 5 0 +}$ & \\
\hline For & 3212 & 8 \\
Blanks & 1033 & 7 \\
Against & 6865 & 25 \\
\hline
\end{tabular}

The Arabization policy has reached one of its aims at school, i.e. replacing French by "Arabic" but it has not succeded at the social levels. Local varieties, i.e. AA and Berber and its varieties are the essential means of communication in Algeria. Besides, French still reigns supreme in the realms of science, tourism, management and arts.

\section{Arabic-French bilingualism}

French is used side by side with MSA in domains such education, the mass-media and administration. Fitouri ${ }^{15}$ states that Arabic-French bilingualism has become necessary for promoting the development of the Maghreb. It is also used to display the social status of the speaker. Within this framework, Akila16 states: (French has become an elitist language, symbol of social success and remains omnipresent in the fields of the bank of economy and the opening up on the universal'. It remains nevertheless the language of the coloniser. Two general trends of attitudes toward bilingualism in Algeria can be distinguished.

The first trend considers Arabic-French bilingualism as a sign of utter alienation, or assimilation to the French language and culture from which Algeria and many Arab counrties suffer. This trend further consider that Arabic-French bilingualism means the domination of French on the one hand and the loss of identity and uproating on the other hand. The second trend is represented by the scientific elite who have received a French or English education and training They view Arabic French bilingualism a sign of openness and a source of enrichment. They equated French with advanced science and technology. French is considered as a link with Europe and the Western World, and therefore a key to the development the country needs. Table 1.5 shows that 31 of my respondants give support to Arabic-French bilingualism on the ground that it is a suitable means of communication. Ony 6 informants are against bilingualismin Algeria (Table 15).

Table 15 Are you for or against Arabic-French Bilingualism in Algeria?

\begin{tabular}{llll}
\hline & \multicolumn{1}{c}{ Age group } & Total & $\%$ \\
\cline { 2 - 3 } & $\mathbf{1 7 / 2 5} \mathbf{2 6 / 3 5} \mathbf{3 6 / 5 0} \mathbf{5 0 +}$ & & \\
\hline For & 7996 & 31 & 77,5 \\
Blanks & 0102 & 3 & 7,5 \\
Against & 3012 & 6 & 15 \\
\hline
\end{tabular}

The criticisms levelled against Arabic-French bilingualism are emotionally rather than factually based. Practically speaking, bilingualism in Algeria will be maintained for many years to come. Research has shown that Arabic-French bilingualism is perceived to be the best language policy for Algeria Grandguillaume, ${ }^{11}$ Haddad. ${ }^{17}$ The Algerian population were so deeply influenced linguistically during the French occupation that, today, more than fourty years after the Algerian independence (1962), French continues to play an important role in spoken as well as in written domains. Many Algerian people understand French and use it in particular situations called situational shifting. Bloom\&Gumperz ${ }^{18}$ where the languages convey social meanings.

\section{Berber}

The government's Arabization policies since the independence have worked towards eroding the importance of Tamazight (more commonly known by the foreign designation of "Berber"), forcing 
the population, which is highly urbanised, through social, educational, and economic pressures (and until 1980's through physical violence and incarceration) to resort to French or the mixed Arabic. The Arabization policy ignores the multilingual nature of the country. The Berber leaders felt threatened by Arab nationalism, mainly the central role it gave to Classical/ModernStandard Arabic at the expense of Berber and they become increasingly vocal in their demands of linguist rights. Nonetheless, Tamazight is still widely spoken as a first language. The Algerian census does not ask information concerning house-hold languages. All language statistics should be taken with suspicion. "Studies" on numbers of Tamazight speakers have only taken into account areas officially disignated as 'Berber', and completely disregarded the high populations of Tamazight speakers in other regions, including entire neighborhoods in Arabic- designated cities such as Oran, Algeriers, etc. Speakers of different Tamazight 'languages' have been known to understand each other. Radio programmes in kabylia have been understood by illiterate women in the Aures, whose version of Tamazight is listed as a separate language (Chaouia). It is also important to note that the new Algerian Constitution represents a historical turn in that it acknowledges Berber as a national language and as an integral part of the unified Algerian linguistic and cultural identity. Article 3a (adopted April 10, 2002) the status of Berber has changed from a spoken non recognized language to a written recognized national language. The most practical measure of this recognition has been the inclusion of the Berber language in the Algerian system of education. Therefore, Berber has become another language that is obligatory for students to learn from the first grade.

\section{Educated spoken arabic}

Educated Spoken Arabic comes out as a result of the linguistic friction between Modern Standard Arabic and Colloquial Arabic. It occupies an intermediate level within the Arabic continuum. ESA relies heavily on MSA and Colloquial Arabic and even some foreign languages. The amalgamation of these codes gives ESA the capacity of being understood by everybody regardless his social and educational background. This flexibility stems from the lexical diversity of ESA. The fact remains that educated Arabs of most nationalities talk among themselves on most topics with little or no linguistic embarrassment Ezzat $^{19}$ carried out a pilot study about the mutual intelligibility between students of various Arab nationalities. He states that: "The question of reciprocal intelligibility has not been raised among these students who conduct their daily affairs in their own dialect.Thus, it occurred to me to investigate the common features that help towards this mutual understanding”. Ezzat ${ }^{19}$

Ezzat gives a brief account of the points of similarity and differences in ESA variety at the level of phonology, grammar and lexis. He concludes that the colloquial usage, i.e.the registered 'mixed' Arabic of the cultured classes provides spoken norms of intercommunication between educated Arabs of different countries. Among Ezzat's obsevations are two: that educated Arabs use hosts of classical words and expressions and make adjustments where be a speaker replaces some of his own dialectal features with their equivalents in the dialect of another speaker in a particular situation. Educated Spoken Arabic is a variety that Arabs are strongly motivated to employ and extend as it will be shown through this Chapter.This tendency is backed up by Mitchell (1974:125). He states that "Yet, it is the virtually unregistered 'mixed' Arabic provide the basis for the koineised Arabic of intercommunication between Arabs of different countries."

\section{The emergence of ESA in Algeria}

Educated Spoken Arabic is the outcome of the competition between MSA and Colloquial Arabic. The emergence of ESA may be attributed to the inadequacy of Colloquial Arabic to cope with the rising tide of mass-education campaigns, on the one hand, and the failure of the majority of the Algerians to use MSA in their spontaneous discussions of all that relates to Pan-Arabic communication as well as to modern life patterns. Bouhadiba ${ }^{20}$ states that the amalgamation of the different varieties in place gives birth to an intermedial level of Arabic: (The phenomenon of varieties fusion in presence wihin the continuum,as well as the Pan Arabic communication worry gave birth to a new form of Arabic"al lugha al wusta" or intermediate Arabic) Bouhadiba. ${ }^{20}$

ESA is one stage in this long-lasting chain of developments because it is certainly not a native language variety of any speaker, and has not yet developed a clearly defined system of its own due to the indeterminacy of its linguistic forms and structures, in addition to stylistic and regional variation.

ESA which has started to develop is likely to establish itself in the years to come as the number of educated people in Algeria is expected to increase as a result of compulsory and free mass-education. It is supposed to bridge the gap between the two varieties, AA and MSA.

ESA has added a third dimension to Arabic diglossia. Nowadays, we have to speak of Arabic "triglossia". Accordingly, we must distinguish between three Arabic varieties: Modern Standard Arabic, Ccolloquial Arabic, and Educated Spoken Arabic. In an attempt to show how the linguistic system of modern Arabic in Algeria works, we propose the following diagram (Figure 1). ESA, consists of a spoken form that borrow entensively from the High veriety, i.e. MSA, and being expressed fluentely in the "Low" variety, i.e. Colloquial Arabic, so as to be intelligible to the uneducated people. Bishai ${ }^{7}$ states that most of the educated people in the Arab world believe that Modern Inter-Arabic is not colloquiallanguage, but a simplified version of Classical Arabic, in which the pausal forms replace the contextual ones.'

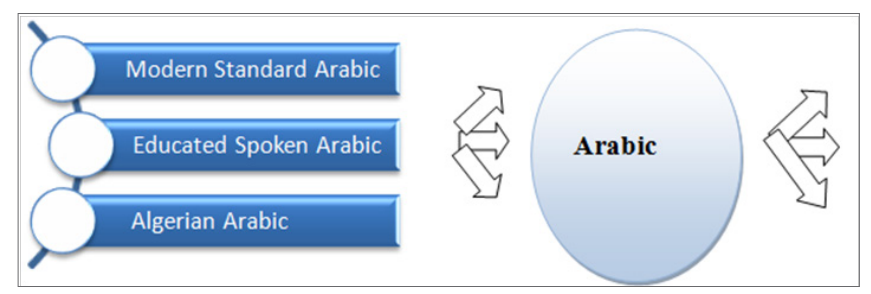

Figure I Different facets of Arabic.

All the structural aspects of ESA are subject to change. Its pronunciation vocabulary, morphological patterns of word formation are involved in this change. The motivation for speakers to choose ESA in certain settings is to portray themselves as educated, to facilitate inter-regional intelligibility, and to show solidarity with speakers from different regions. It provides space for expressing local allegiances because speakers select certain standard forms and at the same time retain other local features of their choice. 


\section{Conclusion}

The socio-political situation in Algeria is both misleading, and a source of conflictual interpretations None of my informants use MSA in their social life. Besides, a foreigner who has studied only MSA will not understand much of the spoken discourse going on around him in Algeria. For the most part, MSA is not used in spontaneous speech situations. Modern Standard Arabic lacks the vitality of AA and Berber. It is used only for specific purposes (see1.3) for it is no one's mother tongue. MSA often intermingles whith AA in what clearly becomes a mixing of linguistic levels, and gives birth to an intermediate level of Arabic generally labelled Educated Spoken Arabic. The latter is assumed to lessen the linguistic friction between the formal MSA and the informal AA variety. ESA has not been fixed by formal codification. This makes the proficiency of this variety fluctuate between the basic competencies of illiterate speakers and those of highly-educated Arabists. Given this complex multilingual situation in which languages compete and overlap for social, economic and political capital, Algeria provides a rich setting for studying the conflict and tensions between languages in Algeria.

\section{Acknowledgements}

None.

\section{Conflict of interest}

The author declares no conflict of intrest.

\section{References}

1. Maamouri M. The Linguistic Situation in Independent Tunisia. American journal of the Arab society. 1973;2(1):1-52.

2. Saïd NF. Lexical Innovation Through Borrowing in Modern standard Arabic. Spain: Princeton Near East Papers; 1967. 123 p.

3. Holes Clive. Arabic Structures; Functions and Varieties. Washington, USA: Georgetown University Press; 2004. 440 p.

4. Bateson MC. Arabic Language Handbook. USA, Washington: MESA; 1967. $3 \mathrm{p}$.

5. Achouch M. Sociolinguistic situation in Algeria in Languages and migration. Louis Daben editor: Algeria; 1981. 464 p.
6. Ennaji M. Aspects of Multilingualism in the Maghreb. International Journal of the Sociology of Language. 1991;87:7-25.

7. Bishai WB. Modern Inter Arabic. Journal of American Oriontal Society. 1996;86(3):319-323.

8. Mazouni A. Culture and Education in Algeria and the Maghreb. Paris: François Maspen; 1969.

9. Haugen E. Language Conflict and Language Planning: The Case of Modern Norway. USA: Hardward University Press; 1966. 393 p.

10. Pride JB, Holmes J. Sociolinguistics: selected Readings Penguin Books. England: Harmondsworth, ringwood; 1972. 381 p.

11. Grandguillaume G. Arabization and Language Policy in the Maghreb. Paris: Paris Library Annex; 1983. 214 p.

12. Saadi N. The Cultural Clashes in Algeria: A disease of identity. In: Maarouf, editor. Algeria: Identity Community; 1995. 450 p.

13. Ibrahimi AT. From Decolonization to the Cultural Revolution. Algeria: SNED press; 1973. $230 \mathrm{p}$.

14. Morsly D. The foreign language: reflection on the status of the French language in Algeria. Algeria: The French in the World 189; 1984. 22-26 p.

15. Fitouri C. Biculturalism, Bilingualism and Education. France: NeuchâtelParis Delachaux \& Niestlé; 1983. 343 p.

16. Akila B. Plurilingualism in Maghred, Collection of Linguistic Legislation in the World. 2001. p. 5-25.

17. Haddad M. Arabization of the teaching of Sciences and Mutations in the sociolinguistic field in Algeria, in New Cultural Enjoyment in the Maghreb. Henry JR, editor. Paris: CNRS; 1986.127 p.

18. BLOM JP, Gumperz JJ. Social meaning in linguistic structure. In: Gumperz JJ, Hymes D, editors. New York: Holt, Rinehart \& Winston; 1972.184 p.

19. Ezzat A. Intelligibility among Arabic Dialects. Iran: Beirut Arab University; 1974. 83 p.

20. Bouhadiba F. Linguistic Continuum or Alternation of Codes Analysis of Dynamics of Facts (State of Place). Synergies Algérie publishers. $1998 ; 1: 1-15$. 